\title{
MEDIO AMBIENTE Y DESARROLLO ¿Un Puente Demasiado Lejos?
}

\author{
David Solano
}

M.A. ESAN

$\mathbf{H}$

oy soplan nuevos vientos para la economía peruana. La reinserción del país en la comunidad económica internacional y la pacificación interna han sido determinantes para la entrada de capitales extranjeros a nuestra economía y para que nuestro mercado de valores sca calificado como el segundo mercado emergente más importante del mundo; en pocas palabras, el Perú está volviendo a cobrar importancia en el ámbito económico internacional. Sin embargo, existe el riesgo de que el desarrollo que se consiga no sea sustentable en el largo plazo; es decir, que los recursos se exploten en forma tan intensa que ya no puedan ser aprovechados por las generaciones futuras.

Los noventas son los años del cuidado del medio ambiente, tema que ha adquirido mayor resonancia después de FCO 92, la Conferencia Mundial de las Naciones Unidas para el Medio Ambiente desarrollada en Rfo de Janciro. En ese encuentro se llegó a la conclusión que la preservación de los ecosistemas no es una moda, sino una obligación de la generación presente, y que el derecho al desarrollo en países como el nuestro "...debe ejercerse en forma que responda a las necesidades del desarrollo y el ambiente de las generaciones futuras" "I.

Por todo esto, los empresarios y el gobierno del Perú deben otorgar prioridad a la previsión de las consecuencias que las inversiones futuras pueden tener sobre el medio ambiente en las condiciones legales, económicas y sociales actuales. No se debe olvidar que nuestro país está dejando atrás 15 años de guerra fratricida cuyo caldo de cultivo fue el descontento social. Impulșar un desarrollo pasajero puede significar reproducir las condiciones para que la historia se repita y los peruanos del futuro vuelvan a vivir aquellos lustros de horror y zozobra.

$1 /$ Principio $3^{\circ}$ de la Declaración de Río sobre Medio Ambiente y Desarrollo. 
El presente artículo intenta brindar una visión global de cómo el tema del medio ambiente está sicndo manejado por el gobierno y los empresarios del Perú, así como advertir sobre las consecuencias que para el desarrollo del país puede tracr la tendencia actual.

\section{1. ¿Existe una política sobre medio am- biente en el Perú?}

Entre sus primeras medidas, el gobierno del presidente Fujimori promulgó, en setiembre de 1990, el Código de Medio Ambiente (CMA, en adelante), buscando sentar las bases para la intervención del país en ECO 92. Sin embargo, posteriormente el propio gobierno se ha encargado de "maquillar" esta ley para no ahuyentara los inversionistas interesados en participar en el proceso de privatización de empresas públicas.

En efecto, el gobierno ha moderado los alcances de ese código, en particular sus mecanismos de coerción, a través de otros instrumentos legales, como: la Ley marco para el crecimiento de la inversión privada (Decreto Legislativo 757, del 13-1191), la Ley de Promoción de Inversiones en el Sector Minero (Decreto Legíslativo 708, del 14-11-91) y la Ley de Promoción de Inversiones en el Sector Hidrocarburos ${ }^{2}$ (Decreto Legislativo 655). Baste citar algunos ejemplos:

2/ Debe tenerse en cuenta que la inversión más sig. nifieativa se preveía precisamente en cstos dos sectores extractivos, que juntos concentran, hasta marzo de 1995, el 44,5 por ciento del monto de inversión al que se han comprometido las empresas adquirientes de empresas privatizadas, Solo son superados por el sector telecomunicaciones (53 por ciento), lo que se explica por el fenómeno que ha significado la compra de la CPT.
- El Artículo 18 del texto original del CMA, que contemplaba la posibilidad de clausura definitiva de las actividades que pudieran provocar daño irreversible al medio ambiente, ha sido tácitamente sustituido por el Artículo 52 del Decreto Legislativo 757, que contempla sólo la suspensión de licencias.

- El Decreto Legislativo 708 ha derogadoel segundo párrafo del Artículo $53 \mathrm{del}$ CMA, que establecía la disolución, pagando un justiprecio, de los contratos cuya cjecución pusiera en peligro la protección o conservación de áreas naturales.

-El Artículo 63 del CMA, que establece usar estándares internacionales para calificar los desechos como de técnicamente aceptables, ha sido modificado por el Decreto Legislativo 708, que establece que dichos estándares sean dictados por la autoridad competente a través de un reglamento, ef cual hasta la fecha (casi 4 años después) no ha sido elaborado.

- El Decreto Legislativo 655 ha derogado el Artículo 71 del CMA, que a la letra decía: "...prohibido desarrollar actividades para el aprovechamiento energético o de recursos naturales no renovables en el ámbito de las áreas naturales protegidas". Es evidente que esta disposición obedeció a la necesidad de eliminar las harreras legales que impedían la exploración petrolera que pretendía emprender la Texas Crude en la Reserva Nacional de PacayaSamiria. Finalmente, este proyecto no llego a llevarse a cabo por las protestas surgidas dentro y fuera del país.

Estos ejemplos muestran que el Estado no ha considerado al medio ambiente como un patrimonio que debe ser protegido, sino como un obstáculo para sus planes. 
Aun más, ha intentado cubrir los vacíos dejados en el CMA con decretos supremos, cuya jerarquía es menor que la de una ley o un decreto legislativo; con este tipo de dispositivo legal se ha reglamentado el tratamiento de residuos y los estudios de impactos ambientales en los sectores de minería, hidrocarburos, electricidad y pesquería.

\subsection{El Conam: solución o burocracia}

Dentro de este panorama de aparente descuido del medio ambiente, llama la atención el que el Gobierno haya creado un ente encargado de velar por el cuidado del patrimonio natural. Este organismo es el Consejo Nacional del Medio Ambiente, Conam.

Lucgo de un arduo debate en el Congreso, entre los miembros de la Comisión de Medio Ambiente (calificada por sus miembros como "benjamín" e incomprendida) y los de la Comisión de Presupuesto, se promulgó la Ley 26410 , que dio partida de nacimiento al Conam.

El Conam ha sido concebido para canalizar el esfuerzo y la cooperación nacional $\mathrm{c}$ internacional hacia el beneficio del medio ambiente peruano. Su función principal será formular, coordinar, dirigir y evaluar la política nacional de medio ambiente, así como velar por su estricto cumplimiento. Está compuesto por tres órganos:

- El consejo directivo, que es la máxima autoridad y está integrado por siete miembros, tres nombrados por el Ejecutivo y un representante de cada uno de los siguientes: gobiernos regionales, gobiernos locales, sectores económicos primarios y sectores económicos secundarios.
Estos cuatro últimos miembros deben ser ratificados mediante resolución de la Presidencia del Consejo de Ministros.

- La secretaría cjecutiva, que es el órgano técnico normativo y está integrado por expertos en materia ambiental.

- La comisión consultiva, integrada por representantes de los sectores público y privado.

Sin embargo, la sola creación del Conam no representa solución alguna para los problemas medio ambientales del país; algunos indicios permiten anticipar las dificultades que este organismo tendrá que enfrentar en su afán de convertirse en el paladín del ambiente y el patrimonio nacional en nuestro país:

Para empezar, hasta ahora no se ha instalado el Consejo, a pesar de que la ley ordena hacerlo a los 60 días de promulgada. El único avance que puede consignarse hasta la fecha es que la Presidencia del Consejo de Ministros ha cumplido con ratificar a los cuatro miembros que le coresponden.

Por otra parte, no existc claridad respecto al procedimiento que debe seguirse para la elaboración del reglamento de la ley de creación. Según micmbros de la Comisión de Medio Ambiente del Congreso, el reglamento debe ser elaborado por el consejo directivo del Conam, el que deberá elevarlo a la Comisión parlamentaria y ésta, a su vez, a la Presidencia del Consejo de Ministros, a la que corresponde emitir el decreto supremo correspondiente.

Todo este largo trámite puede llevar tres o cuatro meses, y mientras tanto ni la 
secretaría cjecutiva ni el comité consultivo pueden operar. Es decir, aparentemente no hay interés en que el Conam funcione antes del término de este primer periodo del gobierno del ingeniero Fujimori. Puede decirse, pues, que el Poder I egislativo no cumple con dotar al Conam de los instrumentos legales para cumplir eficientemente su labor. Si se mantiene esta tendencia, el Conam está destinado a convertirse en un ente burocrático más.

Más allá de estas dificultades iniciales, es de esperarse que el Conam enfrente conflictos de intereses o de competencia con los diferentes ministerios sectoriales (Energfa y Minas, Pesquería, ctc.), razón por la cual se hace necesario que sus tres órganos: directivo, ejecutivo y consultivo, estén integrados por profesionales, no sólo con experiencia en el tema de medio ambiente, sino también con dotes de negociadores. Politizar dichos cargos sería altamente perjudicial para el país.

\section{2 ¿Bastan los reglamentos para pro- teger el medio ambiente?}

Como se ha podido observar, si bien existen leyes destinadas a cuidar el medio ambiente, no están dados los mecanismos que permitan llevarlas a la práctica. Por ejemplo, nuestra legislación no contempla la figura del "delito ccológico"; nuestros códigos de procedimientos - civiles o penales, según se califique el deterioro del medio ambiente- no especifican cómo deben canalizarse las denuncias sobre maltrato a la ecología. Esto origina que nuestro medio ambiente se encucntre tan desprotegido con reglamentos como $\sin$ ellos.

¿Cómo puede, por ejemplo, un ciudadano denunciar los daños que una explota- ción petrolera produce al verter residuos al río de donde obtiene el agua para ricgo? ¿A quién acude, al juez o a la policía? Este es un vacío muy grande que nuestra legislación está en la obligación de llenar, más aun ante la imposibilidad del Estado de vigilar cada rincón del país donde sea posible el daño ecológico.

Quizás pueda argüirse que exigir estudios de impacto ambiental a cualquier tipo de explotación que pretenda establecerse -minera, petrolera, pesquera, etc.significa una preocupación tangible por el medio ambiente. Sin embargo, los estudios de impacto ambiental no son sujetos de verificación en momento alguno, y obviamente, el futuro inversionista puede falscar los datos con el objeto de obtener autorización para su actividad. Fs necesario, entonces, implantar la norma de evaluar estos estudios; la medida no tendría que provocar una reacción adversa en los empresarios, pues, por ejemplo, nadie cuestiona la verificación de los datos financieros de las empresas para fines impositivos.

Es preciso destacar, además, que en la actualidad los empresarios peruanos consideran los estudios de impacto ambiental simplemente como un requisito que debe cumplirse, como un documento más en su expediente. Esto se debe a que la mayoría de los informes resultan demasiado voluminosos, controlistas y poco prácticos porque son llevados a cabo por consultoras contratadas y por técnicos en la materia, no por profesionales acostumbrados a tomar decisiones gerenciales.

En conclusión, sc pucde afirmar que en el país no existe una politica de medio ambiente claramente definida. Los instrumentos legales, dispersos, sin objetivos 
claros y carentes de mecanismos adecuados para aplicarlos, reflejan simplemente que el Gobierno no tiene cabal conciencia de la importancia que el medio ambiente tiene para el desarrollo integral y duradero del país.

El cuidado del ambiente natural es considerado como una actividad consumidora de recursos que puede obstaculizar la libre entrada de capitales extranjeros. Esta visión de corto plazo puede ser causante de numerosos problemas económicos y sociales, tal como se verá a continuación.

\section{Gerentes y medio ambiente}

La carencia de una adecuada política de medio ambiente es responsable también, en cierta forma, de la muy poca importancia que el gerente peruano otorga al ambiente natural como elemento que debe preservarse. Esta actitud contrasta con la observada en otros países latinoamericanos, donde el medio ambiente es una variable que ya está siendo incorporada a la toma de decisiones administrativas.

\subsection{Algunas experiencias internacio- nales en cuidado del medio ambiente: Chile y México}

La globalización de la economía mundial y la creciente competencia en el comercio mundial son unas de las razones que impulsan a los países latinoamericanos a proteger el ambiente natural.

En efecto, una de las condiciones impucstas por Estados Unidos a México para la firma del Tratado de Libre Comercio (TLC) fue que éste último pusiera en práctica normas que permitan proteger el medio ambiente, sobre todo en las zonas de frontera. Aunque la normatividad legal en esta materia ya existía en México, los estándares en cuanto a contaminación permitida son considerados muy teóricos y poco prícticos, lo que acarrea grandes dificultades al momento de su aplicación y origina que la capital, México D.F., sea una de las ciudades con más alto nivel de polución urbana en el mundo.

Esta experiencia mexicana ha hecho que Chile (cuyo afán de ingresar al TLC sigue vigente) tome medidas para proteger el ambiente natural. Precisamente en 1994 . el gobierno de Patricio Aylwin promulgó la Ley de Bases de Medio Ambiente. En contraste con lo que se realizó en México, este país busca ir creando paulatinamente un marco legal que permita aplicar medidas prácticas, pues imponer restricciones severas, difíciles de cumplir, scría poco acertado en un país cuya gran producción de cobre y gran cantidad de refinerías lo convierten en el mayor emisor de díxido de azufre del hemisferio sur.

\subsection{El cuidado del medio ambiente pa- ra el gerente peruano}

En 1993, la revista América Economía publicó los resultados de una encuesta realizada en 1992 a los principales cjecutivos de las mayores empresas de cinco pafses latinoamericanos (México, Brasil, Chile, Colombia y Perú). Presentamos algunos resultados de ese estudio, de los cuales se infiere que el Perú es el país donde los gerentes muestran una menor preocupación por el medio ambiente:

- Respecto a si la empresa participaba en alguna organización de protección al medio ambiente, 82 por ciento de los gerentes entrevistados en el Perú respondió que no. El porcentaje promedio (conside- 
rando los cinco países) de los gerentes entrevistados que respondieron así fue de 56 por ciento.

- En el Perú, el 32 por ciento de los gerentes encuestados manifestó que no tenía preocupación alguna por el medio ambiente. El porcentaje promedio (considerando los cinco países) de los entrevistados que dieron esta respuesta fue de sólo 7 por ciento.

- Interrogados sobre qué se había hecho en su empresa para que sus actividades no deterioren la calidad de vida de la comunidad, 32 por ciento de los gerentes peruanos constestó que nada y 19 por ciento no dio respuesta alguna. El porcentaje promedio (considerando los cinco países) de los entrevistados que dieron esta respuesta fue de 6,8 por ciento.

- El 73 por ciento de los gerentes peruanos manifestó que en sus empresas no se había tomado iniciativa alguna para proteger el medio ambiente. El porcentaje promedio (considerando los cinco parses) de los entrevistados que dieron csta respuesta fue de 24 por ciento.

- Sobre la preocupación que perciben en el gobierno de su país con relación al medio ambiente, 87 por ciento de los gerentes peruanos marcóel rango "entre poco y nada". El porcentaje promedio (considerando los cinco países) de los entrevistados que marcaron el mismo rango fue de 49 por ciento.

- Ninguna de las empresas entrevistadas en el Perú cuenta con una gerencia o una subgerencia de Asuntos Ambientales. El porcentaje promedio (considerando los cinco paises) de las que no cuentan con esta unidad es de 78 por ciento.
- El 50 por ciento de los gerentes entrevistados en el Perú cree que no se verá afectado económicamente si no protege el medio ambiente. El porcentaje promedio (considerando los cinco países) de los entrevistados que opinaron así fue de 35 por ciento.

- El 73 por ciento de los gerentes peruanos opinó que no se toman medidas para proteger el medio ambiente por falta de legislación drástica. El porcentaje promedio (considerando los cinco países) de los gerentes que opinaron así fue de 53 por ciento.

Como puede apreciarse, la diferencia entre los resultados del Perú y los del promedio de América Latina en todos los ítem anteriores pone de manifiesto la relativa mayor despreocupación del gerente peruano respecto de la conservación del medio ambiente. Esta falta de conciencia no deja de ser alarmante si se piensa en la magnitud de la riqueza natural que requiere protección en nuestro país.

\subsection{Razones prácticas por las cuales el gerente peruano debe preocuparse por el medio ambiente}

Aunque no se mencione explícitamente, gran parte de la indiferencia que se advierte en el Perú respecto de la necesidad de preservar el medio ambiente se explica por la idea equivocada de que esta preocupación responde sólo a ideales románticos. Sin embargo, por lo que a la empresa se refiere, la globalización de la economía que caracteriza al mundo de hoy debe ser motivo suficiente para prestar la debida atención a este tema.

En primer lugar están las restricciones comerciales que se imponen c impondrán 
en el futuro a los productos de países que no cuidan el medio ambiente. El principal argumento de quienes sostienen la existencia del eco dumping es el subsidio indirecto que países como el nuestro otorgan a las empresas al no exigirles inversiones para proteger la ecología, lo cual perjudica a las empresas de países donde sí existe esta obligación.

Un caso ilustrativo es el de los productores de cobre de Estados Unidos, que pidieron a la International Trade Commission se estableciera una sobretasa arancelaria a las importaciones de cobre chileno, alegando que las fundiciones del país sureño no tenían que cumplir los controles de emisión de las plantas estadounidenses.

Un segundo motivo para tomar en serio el cuidado del medio ambiente es la consigna que actualmente existe en los organismos multilaterales de crédito para no votar favorablemente por proyectos de los cuales no se haya recibido estudios de impacto ambiental antes de los 120 días del momento previsto para la votación; este es el caso del BID, cuyos representantes en nuestro país han manifcstado la intención de otorgar créditos a empresas particulares para llevar a cabo proyectos de infraestructura vial, turística, entre otras actividades. Se prevé que esta norma se extenderá a todos los organismos de crédito y que para el otorgamiento de fondos a empresas en marcha se verificará que éstas no produzcan daño presente o potencial al medio ambiente.

Una tercera consideración a favor del cuidado del medio ambiente es que acumular pasivos en este aspecto sería perjudicial para la venta de acciones de una empresa, con mayor razón si se busca co- locarlas en el mercado internacional. Los compradores potenciales pueden verse desanimados de adquirir empresas que requieran de inversiones significativas para reducir la depredación de los recursos; ésta fue una de las razones que impidieron la venta de Centromín Perú en 1994.

Por otro lado, depredar los recursos es una fuente de tensiones sociales y en algún momento puede repercutir desfavorablemente en el ambiente externo de la empresa. No debe olvidarse que generalmente los trabajadores son miembros de la comunidad de la cual se obtienen los recursos y pueden ser negativamente afectados. No cuidar el medio ambiente requerirá en algún momento de inversiones cuantiosas para recuperarlo y representará un mayor costo para la empresa. Piénsese $\mathrm{cn} \mathrm{cl}$ caso de la empresa Southern Peru Copper Corporation y la ciudad de Ilo.

\section{Hacia un plan nacional de medio ambiente}

Para lograr la unidad nacional respecto del cuidado del patrimonio natural es nẹcesario tomar conciencia de que desarrollo $y$ medio ambiente se complementan; no habrá un verdadero desarrollo si no se preserva el medio ambiente, pues si se agotan los recursos que hoy sostienen la economía, mañana habrá una situación de miseria generalizada.

Frente a esta situación, el Estado está en la obligación de promover tecnologías "limpias" que aseguren la explotación de los bienes del país y, a su vez, contribuyan a prescrvarlos, para que las generaciones futuras puedan disfrutar de oportunidades similares a las disponibles en la actualidad. 
No debe olvidarse que el descontento social que puede acarrear el sentimiento de despojo en zonas depredadas puede convertirse en el mejor caldo de cultivo para el rebrote de la violencia social de la cual el país viene recuperándose. Esto debe ser tomado en cuenta por un Estado que husque la paz social y por los gerentes que deseen empresas armónicas con sus entornos inmediato y mediato.

A la luz de la Declaración de Río sobre Medio Ambiente, el Estado debe promover el uso racional de los recursos. La gran interrogante es cómo hacerlo, ya que lograrlo requiere la conjunción de una serie de medidas. Algunas de las acciones que podrian tomarse son las siguientes:

- Obligar a las empresas a presentar periódicamente auditorías sobre el medio ambiente donde desempeñan sus actividades. La diferencia con la legislación vigente sería no sólo el carácter conminatorio de la medida, sino la verificación a la que se someterían esos informes y las sanciones que se establecerían, con la posibilidad de clausurar actividades si se incumple (por no presentación o por falsificación de datos) con la exigencia. Para esto scría nccesario legislar el cuidado del medio ambiente en las industrias manufactureras asentadas en el territorio nacional, tal como se ha hecho con las empresas pertenecicntes a los sectores hidrocarburos, minería, electricidad y pesquería.

- Crear a la brevedad un cnte que cumpla las funciones de Superintendencia de Medio Ambiente, con facultades para fiscalizar y sancionar la depredación de los ecosistemas. Esta labor debe ser desempeñada por el recientemente creado Con- sejo Nacional de Medio Ambiente, Conam.

- Crear organismos que canalicen la participación de la población (individualmente o a través de grupos organizados) en la preservación del medio ambiente, para evitar la formación de una policía ambiental que podría convertirse en un ente burocrático. Esto tendría que ser precedido por toda una campaña de concientización de la ciudadanía - con la inversión y los canales adecuados- sobre la importancia que el medio ambiente tiene para las generaciones futuras.

- Tener en cuenta que todo aquel que presenta una denuncia puede desalentarse a seguir colaborando si el infractor no recibe un castigo ejemplar. Por esto, la legislación debe ser mucho más clara y enfática en cuanto a mecanismos de denuncia y sanciones a personas naturales y jurídicas que depredan el medio ambiente.

Por supuesto, todo lo anterior debe estar acompañado por un plan de largo plazo de educación a la niñez en el respeto a los ecosistemas y a las otras formas de vida, que en buena cuenta significa el respeto a los derechos de los demás. Se debe desterrar de las futuras generaciones la cultura del aprovechamiento irracional de lo que no tiene un costo directo.

Noobstante, es necesario señalar que la aplicación de estas medidas requiere la voluntad política del Gobierno, el que a través de dispositivos y de mecanismos de concertación puede inducir a tender el puente entre el desarrollo actual del país y las necesidades y derechos de las nuevas generaciones. 


\section{Bibliografia}

CEPAL, Reseña de documentos so. rrollo ambientalmente sustenta tiago de Chile, CEPAL, 1992.

\section{GRUPO TEMATICO DE MEDIO A} TE DE ONG, Rio 92: tratados vos, Lima, junio, 1993.

PERU, Decreto Legislativo 655: Le moción de inversiones en el sec carburos.

...., Decreto Legislativo 693: Ley d ción de inversiones en el sector $\mathrm{e}$

...-. Decreto Legislativo 708: Ley d ción de inversiones en el sector

2... Decreto Legislativo 757: Ley mat erecimiento de la inversión priva

.... Decreto. Sunremn M32.97.FM. R

...., Decreto Supremo 050-92-EM Reglamento de procedimientos mineros.

RODRIGUEZ, Andrés, "Desarrollo y calidad de vida", Medio Ambiente, Lima, (62): 10 11, oct.- dic., 1994.
7- I SALAZAR, C.R., "Conferencia de las Nacio-

1- nes Unidas sobre medio ambiente y desarrollo", Polftica Internacional, Lima, (29): 90-95, jul.- set., 1992.

SOCIEDAD PERUANA DEDFRECHO AMBIEN'TAL, Código del Medio Ambiente, Lima, diciembre, 1992.

STOUB, Jeffrey, "Medio ambiente: Iento pero seguro", América Economía. (89): 80-83. nov., 1994.

"Convenio sobre diversidad biológica, aprobado en Río de Janeiro el 5 de junio de 1992", Política Intemacional, Lima, (29): 128 . 135, jul.-set., 1992.

"Declaración de Río sobre medio ambiente y desartollo", Polfitica Internacional, L.ima, (29): 121-127, jul-set., 1992.

Desarrollo económico y la protección ambiental, Gestión (Lima), 22-11-94.

"Medio ambiente: iy qué piensan los empresarios?". América Economía, (74):45-49, jul., 1993. 